\title{
Meditation Awareness Training for Individuals with Fibromyalgia Syndrome: an Interpretative Phenomenological Analysis of Participants' Experiences
}

\author{
William Van Gordon $^{1} \cdot$ Edo Shonin $^{1} \cdot$ Mark D. Griffiths $^{1}$
}

Published online: 6 November 2015

(C) Springer Science+Business Media New York 2015

\begin{abstract}
Fibromyalgia syndrome (FMS) is a complex and poorly understood psychosomatic pain disorder. The illness has been the subject of controversy, both in terms of the alleged lack of interest and capability of the medical community to understand and support patients with FMS, and the burden that such individuals place upon economic and healthcare resources. Due to the lack of convincing data for the effectiveness of extant pharmacological and non-pharmacological FMS treatments, a recent direction in FMS research has been the empirical investigation of mindfulness and other meditation-based approaches. The present qualitative study explored whether following participation in a mindfulnessbased intervention, patients with FMS report experiencing changes in (i) how they experience and relate to their illness and (ii) their attitudes towards societal participation, work and unemployment. Ten individuals with FMS were randomly selected from the intervention arm of a randomised controlled trial (RCT) evaluating the effectiveness of a mindfulnessbased intervention known as Meditation Awareness Training (MAT) for the treatment of FMS. Transcripts of semistructured interviews were analysed using Interpretative Phenomenological Analysis, a robust and rigorous qualitative methodology for analysing subjective experiences. Five super-ordinate themes emerged from the dataset: (i) reservations about participating, (ii) improvements in psychosomatic well-being, (iii) spiritual growth, (iv) awareness of impermanence and (v) increased sense of citizenship. MAT was experienced as both an acceptable and accessible
\end{abstract}

William Van Gordon

william@awaketowisdom.co.uk

1 Division of Psychology, Nottingham Trent University, Burton Street, Nottingham, UK intervention by individuals with FMS, and participants reported experiencing improvements in psychosocial functioning as well as an increased sense of societal responsibility. MAT appears to have utility for treating FMS and for changing the attitudes of some individuals with FMS towards community engagement and societal contribution.

Keywords Fibromyalgia syndrome $\cdot$ Pain disorder . Psychosomatic well-being $\cdot$ Depression $\cdot$ Fatigue $\cdot$ Meditation Awareness Training $\cdot$ Mindfulness $\cdot$ Attitudes towards work Interpretative phenomenological analysis

\section{Introduction}

Fibromyalgia syndrome (FMS) is a poorly understood chronic pain disorder involving symptoms of widespread musculoskeletal pain, non-restorative sleep, sleep disturbance, cognitive dysfunction and fatigue (Häuser et al. 2012). FMS is frequently associated with functional mobility limitations, poor quality of life, psychopathology (in particular anxiety and depression) and irritable bowel syndrome (Wolfe et al. 2013). Individuals with FMS can incur up to three times the medical expenditure compared to chronic illness comparison groups (Wolfe et al. 1997a; Jones et al. 2012). Prevalence estimates for FMS are in the order of $2.9 \%$, with higher rates in females compared to males (Branco et al. 2010).

According to Wolfe (2009), FMS is a highly controversial condition. In conjunction with a broad symptom spectrum, the absence of a reliable laboratory test for FMS has led some individuals (both medical professionals and members of the public) to doubt and/or question the legitimacy of the condition. In other words, because a diagnosis of FMS is reliant upon the exclusion of other illnesses as well as the patient's medical history and their verbal responses to pressure being 
gently applied to tender points, it is difficult to definitively establish that a given individual is experiencing the illness. Furthermore, efforts to dispel what might be described as 'stigma' relating to the condition are not helped by the fact that FMS is associated with (i) high rates of presenting at medical services (Schaefer et al. 2011), (ii) unemployment (Scott and Jones 2014), (iii) use of social security (and in particular incapacity for work and/or disability) benefits (Sicras-Mainar et al. 2009; Wolfe et al. 1997b) and (iv) hypochondriasis (Canzonieri et al. 2013).

Recommended front-line pharmacological treatments for FMS include the tricyclic antidepressant amitriptyline and serotonin-norepinephrine reuptake inhibitors such as duloxetine and milnacipran (Häuser et al. 2012). However, the efficacy of pharmacological treatments for FMS is questionable. Whilst a small number of patients experience substantial symptom reduction, many patients discontinue treatment due to limited symptom relief and/or adverse effects (Häuser et al. 2012; Nüesch et al. 2013). Consequently, the current treatment of choice for FMS is a multicomponent approach involving psychopharmacology with (for example) aerobic exercise, cognitive-behavioural therapy, lifestyle change, self-help, and/or psycho-education (Nüesch et al. 2013).

Consistent with the absence of convincing outcome data for the effectiveness of extant FMS treatments, in recent years, emphasis has been placed upon the empirical validation of novel non-pharmacological treatments that do not incur the same adverse effects as pharmacotherapy. An important direction in this respect has been the empirical investigation of mindfulness and other meditation-based approaches (Henke and Chur-Hansen 2014; Langhorst et al. 2013; Lauche et al. 2013). Mindfulness involves regulating ruminative thought processes by focussing awareness on the present moment. It is described as "the process of engaging a full, direct, and active awareness of experienced phenomena that is (i) spiritu$\mathrm{al}$ in aspect and, (ii) maintained from one moment to the next" (Shonin and Van Gordon 2015, p. 900). Based on metaanalytical findings, a mindfulness-based intervention (MBI) known as mindfulness-based cognitive therapy (MBCT) is advocated by the UK's National Institute for Health and Care Excellence (NICE) and the American Psychiatric Association (APA) for the treatment of recurrent depression in adults (APA 2010; NICE 2009). Similarly, a growing evidence base exists for the use of MBIs in treating each of the other key symptoms of FMS including anxiety (Vøllestad 2015), chronic pain (Chiesa and Serretti 2011; Cramer et al. 2012), sleep disturbance (Britton et al. 2012), fatigue (Rimes and Wingrove 2013) and cognitive dysfunction (Stange et al. 2011).

Research assessing the efficacy of mindfulness as a treatment for FMS is still at an early stage, and outcomes have been undermined by issues of poor methodological quality. Nevertheless, preliminary findings show a degree of promise.
For example, a meta-analysis (comprising six controlled trials involving individuals with FMS; $n=674$ ) concluded that mindfulness-based stress reduction (MBSR) led to shortterm improvements in quality of life and pain compared to treatment-as-usual or active control comparison groups (Lauche et al. 2013). More recently, a systematic review (comprising ten randomised controlled trials [RCTs], retrospective studies and longitudinal studies involving individuals with FMS; $n=702$ ) incorporated a range of MBIs and concluded that although there appear to be mild-to-moderate salutary effects, further research is required (Henke and Chur-Hansen 2014).

Davis and Zautra (2013) proposed that the absence of robust and conclusive data from mindfulness-based FMS treatment studies is due to the fact that MBIs require adaptation in order to target a greater range of symptoms over and above somatic pain. More specifically, Davis and Zautra suggested (and then empirically demonstrated) that more effective treatment outcomes can be realised by targeting deficits in positive affect and social relations (i.e. in addition to pain frequency and intensity). FMS is a complicated multi-dimensional illness, and the findings of Davis and Zautra suggest that there is a clear need for greater understanding in terms of the various components that make a given MBI an effective treatment for FMS. In particular, in addition to changing how individuals with FMS relate to their pain (and other symptoms), it appears that mindfulness-based treatments for FMS need to be (i) purpose-designed, (ii) orientated towards helping patients exploit social and metacognitive resources in order to foster better illness and life-coping skills and (iii) based upon a patientled and in-depth knowledge of the illness.

Rather than RCT (and other efficacy-based) study designs, qualitative research is generally understood to be a more suitable means of evaluating how participants experience and relate to a given intervention. Specific methods of qualitative enquiry provide greater insight into the 'life-world' of the patient (Smith et al. 2009), which is essential when attempting to formulate treatments for aetiologically complex and poorly understood psychosomatic conditions such as FMS. In terms of qualitative research involving individuals with FMS, to date, a small but growing number of studies have explored the impact and characteristics of the condition from the patients' point of view (see review by Sim and Madden 2008). However, to the authors' knowledge, no study has ever been undertaken that employs robust and rigorous qualitative analysis in order to investigate the subjective experiences of FMS sufferers participating in an MBI.

The primary aim of the present study was to utilise a rigorous qualitative methodology in order to examine how individuals with FMS experience participating in a purpose-designed MBI. The focus of this primary aim was to explore whether following receipt of mindfulness training, participants report experiencing changes in how they relate to their illness, 
including whether they experience improvements in life- and illness-coping skills. A further aspect of this first aim was to investigate how individuals with FMS experience and assimilate the practice of mindfulness, and examine which components of the intervention are experienced to be the most effective. In light of the apparent tendency for some individuals diagnosed with FMS to have limited aspiration and/or ability to contribute to the socio-economic welfare of their local and wider community, a secondary aim of the study was to explore whether following participation in an MBI, patients report experiencing changes in how they relate to and experience societal participation, work and/or unemployment.

\section{Method}

\section{Participants}

Computer-generated numbers were used to randomly select ten participants from the intervention arm $(n=54)$ of an RCT assessing the effectiveness of a modified version of an MBI known as Meditation Awareness Training (MAT) for the treatment of FMS. Participants were English-speaking adults with a current diagnosis of FMS (as confirmed by a letter from a general practitioner [GP], rheumatologist or hospital pain consultant). Participation was on a voluntary basis, and individuals were recruited into the RCT via GP and hospital referral, FMS self-help groups and strategically placed poster advertisements (e.g. in GP surgeries).

Based on the pre-defined inclusion/exclusion criteria for the RCT, all participants were not currently (i) undergoing formal psychotherapy, (ii) practising mindfulness or meditation, (iii) undergoing changes in psychopharmacology type or dosage (although stable prescription medication was permitted) or, (iv) diagnosed with a neurological disorder. Participant demographic characteristics are summarised in Table 1. Ethical approval for the study was granted by the research team's university ethics committee.

\section{Procedure}

Interpretative Phenomenological Analysis (IPA; Smith et al. 2009) was used to explore the subjective experiences of FMS sufferers based on their participation in MAT. IPA is influenced by phenomenology in its emphasis on subjective experience but also by symbolic interactionism in its appreciation that insight into the meaning individuals ascribe to their experiences can only be gleaned through a process of interpretation (Hamill et al. 2010). IPA can be described as being (i) idiographic because of its focus on how individuals allocate meaning to their experiences, (ii) inductive because it allows themes to naturally emerge from the dataset and (iii) interrogative because it encourages a dialogue to emerge that evaluates how outcomes fit with extant theory and research (Hamill et al. 2010).

Mindfulness and meditation are subtle practices that require the mobilisation of attentional skills that which, for most individuals, remain largely inactive during normal cognitive functioning (Shonin and Van Gordon 2015). Consequently, individuals new to meditation are invariably without a benchmark against which to compare or contextualise their meditational experiences. The hermeneutic phenomenological approach used in IPA is a suitable method for analysing meditative experiences because it lends itself to a rich coconstruction of the meaning individuals ascribe to their meditative experiences by researchers who are themselves proficient in meditation (Shonin et al. 2014a). This allows for findings to be reflexively interpreted within the context of a 2,600year-old spiritual practice system without losing sight of the uniqueness of the participant's experience and the importance that they assign to it (Shonin and Van Gordon 2015).

Programme Description MAT is an 8-week secular intervention delivered by experienced meditation instructors (Van Gordon et al. 2014). Participants attend eight workshops (each lasting $2 \mathrm{~h}$ ) and receive a CD of guided meditations to facilitate daily self-practice. The weekly sessions comprise three distinct phases: (i) a taught/presentation component (approximately $40 \mathrm{~min}$ ), (ii) a facilitated group-discussion component (approximately $25 \mathrm{~min}$ ) and (iii) a guided meditation and/or mindfulness exercise (approximately $25 \mathrm{~min}$ ). In the current study, three breaks (each of approximately 10-min duration) were interspersed into each of the weekly sessions. In the third and eighth week of the programme, participants attend one-toone support sessions (approximately 50-min duration) with the programme instructor.

MAT belongs to what have been termed the second generation of MBIs (Singh et al. 2014; Van Gordon et al. 2015). Unlike first-generation MBIs such as MBSR and MBCT, MAT is overtly spiritual in nature and follows a comprehensive approach to meditation. The teaching of mindfulness is an integral part of MAT, but it is not the exclusive focus. In addition to mindfulness, MAT incorporates techniques followed by ancient Eastern meditation traditions including practices aimed at cultivating (i) citizenship, (ii) perceptive clarity, (iii) ethical and compassionate awareness, (iv) meditative insight (e.g. into subtle concepts such as emptiness and impermanence), (v) patience and (vi) generosity (e.g. of one's time and energy).

In addition to additional 10-min breaks, the intervention was modified in the current study to include an extended focus on (i) mindfulness techniques specifically concerned with meditatively observing and objectifying somatic pain, (ii) compassion meditation in order to help participants become less preoccupied with their illness (i.e. by becoming more aware of the suffering of others) and (iii) citizenship (and the 
Table 1 Participant demographic characteristics

\begin{tabular}{|c|c|c|c|c|c|c|c|}
\hline Participant number & Age & Sex & Education & Marital status & Ethnicity & $\begin{array}{l}\text { Pre-intervention } \\
\text { employment status }\end{array}$ & $\begin{array}{l}\text { Years diagnosed } \\
\text { with FMS }\end{array}$ \\
\hline 1 & 64 & $\mathrm{~F}$ & School leaver & Widow & White (British) & Unemployed & 8 \\
\hline 2 & 50 & $\mathrm{~F}$ & School leaver & Divorced & White (British) & Unemployed & 5 \\
\hline 3 & 52 & $\mathrm{~F}$ & School leaver & Married & White (British) & Unemployed & 11 \\
\hline 4 & 56 & $\mathrm{~F}$ & School leaver & Divorced & White (British) & Unemployed & 9 \\
\hline 5 & 51 & $\mathrm{~F}$ & School leaver & Married & White (British) & Unemployed & 3 \\
\hline 6 & 29 & $\mathrm{~F}$ & School leaver & Married & White (British) & Unemployed & 2 \\
\hline 7 & 62 & $\mathrm{~F}$ & School leaver & Single & White (British) & Unemployed & 6 \\
\hline 8 & 60 & M & School leaver & Married & White (British) & Unemployed & 8 \\
\hline 9 & 35 & $\mathrm{~F}$ & University graduate & Married & White (British) & Employed & 4 \\
\hline 10 & 49 & $\mathrm{~F}$ & School leaver & Divorced & White (British) & Unemployed & 7 \\
\hline
\end{tabular}

practice of 'engaged mindfulness') in order to raise participants' awareness of the benefits (to both themselves and others) of contributing to the welfare of society in a manner that does not exceed the physical and/or psychological demands of their condition.

Data Collection Data collection (and analysis) followed a similar procedure to that employed in previous studies of MAT that have utilised IPA (e.g. Shonin and Van Gordon 2015; Shonin et al. 2014a). The second of the aforementioned one-to-one support sessions (i.e. in week 8 of the intervention) included a semi-structured interview (SSI) designed to derive understanding into participants' experiences of practising mindfulness, including their recollection of how MAT changed their attitudes towards FMS and life more generally. Examples of some of the questions included in the SSI are 'What were your expectations of the course?', 'Did the course differ from these expectations?', 'Has the type or amount of pain that you experience changed since learning to practise meditation?', 'Has meditation changed your ability to cope with FMS? (If yes, then in what ways?)', 'Do you think you will experience any challenges in terms of continuing with the practice after the end of the course?' The MAT instructor used discretion to discern the most suitable point to intersperse the SSI questions into the one-to-one support session dialogue. A Socratic questioning method was employed in order to encourage participants to freely express themselves, and participants were prompted for further clarification as required (Smith 1995). The one-to-one support sessions were audio recorded and then transcribed verbatim.

\section{Data Analysis}

Transcripts were read several times and coded to identify outcomes of experiential significance to the participant. Patterns of meaning were identified for each participant, and transcripts were then assessed for divergence and convergence
(Dennis et al. 2013). The entire analytical process, from reading the raw data through to identifying themes, was repeated in iterative fashion until saturation was achieved (Smith 2004). The analytical process was then repeated by a second member of the research team as a form of independent audit (Smith 1996). Finally, validation techniques such as grounding in examples and requesting feedback from participants on the summary of themes were employed (Creswell 2007; Sandelowski and Barroso 2002; Yardley 2000).

\section{Results}

The analysis of participant's transcripts generated five superordinate themes, each with two subordinate themes. The final hierarchical thematic structure is shown in Table 2, and a description of the emerging super-ordinate and subordinate themes (including illustrative verbatim extracts) is provided below.

\section{Reservations About Participating}

All participants expressed reservations about receiving the intervention. The most common reservation related to a limited understanding of mindfulness (subordinate theme 1a) and an association that participants had made between mindfulness and the supernatural. For example, participants 3, 8 and 10 were under the impression that mindfulness was a means of communicating with the deceased:

I thought mindfulness was when you all sit around and talk with the dead (participant 3)

[Mindfulness] can make you see ghosts (participant 8) My friend did mindfulness and saw her dead aunt (participant 10) 
Table 2 Master and subordinate themes

\begin{tabular}{ll}
\hline Master theme & Subordinate theme \\
\hline 1. Reservations about participating & 1a. Limited understanding of mindfulness \\
& 1b. Fear of losing diagnosis \\
2. Improvements in psychosomatic well-being & 2a. Improved ability to cope with pain \\
& 2b. Improved quality of life \\
3. Spiritual growth & 3a. Spiritual curiosity \\
& 3b. Sense of being on a journey \\
4. Awareness of impermanence & 4a. The uncertainty of life \\
& 4b. Death awareness \\
5. Increased sense of citizenship & 5a. Greater motivation to contribute towards \\
the well-being of society
\end{tabular}

Participant 1 was under the impression that mindfulness involved chanting 'for hours on end in order to see white lights', and participants 2 and 4 believed that mindfulness was a means of developing clairvoyant powers. Other participants (5 and 7) associated mindfulness with the practice of voodoo, and participant 6 believed that mindfulness was a technique for 'reading people's minds'. In addition to associations with the supernatural, some participants $(1,6$ and 10$)$ harboured concerns that mindfulness was a method of brainwashing or 'making people tell the truth' (participant 10). Participants (all except participant 3 ) also expressed concerns as to the demand characteristic of the programme:

How am I going to be able to sit still with my eyes closed for two hours? (participant 2)

I don't mind giving it a try but don't be surprised if I just get up and walk out if the pain kicks in (participant 5) I'm worried that being here for two hours will drain me for the rest of the day (participant 8)

Although participants demonstrated a poor understanding of mindfulness (which in some cases involved being unconvinced as to its suitability or credibility as an FMS treatment), five of the participants appeared to be anxious that the intervention might be effective. When prompted for clarification regarding this concern, participants explained that it related to a fear of losing the diagnosis of FMS (subordinate theme $1 \mathrm{~b}$ ):

It took me three years to get [this diagnosis of] fibro, and when I got it, it was such a relief. If this [MAT] works, I'm not going back to how things were (participant 1) What am I supposed to do if [MAT] works? (participant 3) I'm worried I'll lose my diagnosis and have to work (participant 6)

If mindfulness makes me better, can I still go to the fibro [self-help] group? (participant 7)

Do I have to tell people if I get fixed? (participant 10)

\section{Improvements in Psychosomatic Well-Being}

As participants matured in their understanding and practice of meditation, they reported experiencing improvements in psychosomatic well-being. Three participants (4, 6 and 9) specifically reported reductions in pain intensity and/or frequency as a result of their participation in MAT:

I'm definitely noticing that there is less pain now (participant 4)

The pain is the same in the evening when I'm tired, but it has eased off in the mornings (participant 6)

I used to ache even just after walking the dog but its better now (participant 9)

However, although a small number of participants reported reductions in pain, all participants reported that MAT improved their ability to cope with pain (subordinate theme 2a). Participants mostly attributed this to improvements in their ability to objectify pain and not to allow it to dominate their thought processes:

The pain is still there. However, I am coping with it much better now (participant 1)

When I am tired it still gets on top of me ... But when I'm feeling good, I can just sit with my breath and watch it. It's there and is part of me. But it's also separate from me (participant 8)

'You don't realise just how much [pain] brings you down. It gets in your head and takes over. Everything becomes black and a struggle. It's different though when I practise meditation. It's like I'm a spectator' (participant 10)

More specifically, participants appeared to acknowledge that although pain imposed a significant burden upon their lives, they still had choices in terms of how they relate to their pain: 
I see the pain except now I know I have a choice. I can either let it control my life or I can be in control (participant 2)

The pain is always going to be there but we [the participant and their pain] can work together. I never thought it would be possible (participant 5)

I see what I'm doing to myself and that I've the option to change my thoughts (participant 9)

Participants reported that their enhanced ability to cope with pain lead to improvements in quality of life (subordinate theme $2 b$ ). These improvements mostly manifested as increased levels of psychological well-being. Phrases such as 'I'm happier now' (participants 2, 3, 5 and 6), 'it's much better now' (participants 1, 6 and 7), 'more alive' (participants 4, 7 and 10), 'more energy' (participants 8 and 10) and 'feeling well' (participants 4 and 9) were used to describe this aspect of the participants' experience. Participants also appeared to relate these improvements in quality of life to increases in sleep quality:

I'm sleeping better now (participant 3)

I meditate just before going to bed. I used to wake up about every hour but now I'm only waking up two or three times [per night] (participant 6)

I am able to take a nap during the day which I could never do before. I've got more energy in the evenings now (participant 7)

\section{Spiritual Growth}

Related to the improvements in psychosomatic well-being that the participants experienced as part of theme 2, participants also reported that MAT caused them to grow in spiritual awareness. All participants (except participants 6 and 9) considered this growth in spiritual awareness to be a key determinant of psychosomatic well-being. For example, participant 2 explained that 'when I feel nourished spiritually, I feel better all over', and participant 7 stated that 'meditation soothes the soul and that's why I feel better'. Consistent with these experiences, MAT appeared to lead to an increase in spiritual curiosity (subordinate theme 3a), which is perhaps best captured by the following excerpt from participant 5 :

Normally my mind just does its own thing and I don't notice it. I work myself into a mess without even knowing it. But by just sitting and being with myself, I'm starting to realise that there is this whole other part of me. I'm in my 50s and I'm only just beginning to work it out. It's a really interesting part of my life and I'm curious to know more (participant 5)
Increased curiosity into the spiritual aspect of their being appeared to give participants the sense of being on a journey (subordinate theme 3b). Examples of some of the phrases utilised by participants in this respect are 'journeying within' (participants 2, 5, 9 and 10), 'spiritual journey' (participants 2, 6 and 7), 'walking a path' (participants 1 and 3 ) and 'come a long way' (participants 4 and 8). Participant 2 explained their experience of being on a spiritual journey as follows:

I keep falling back into my old ways but I'm definitely getting stronger. I've got something to work towards now. I'm on a spiritual journey and it's probably the most important thing I've ever done in my life. [Meditation] is like taking a spiritual shower. Being in the here and now helps me to feel whole again. It helps me to know what direction I should go in (participant 2)

\section{Awareness of Impermanence}

The growth in spiritual awareness that participants experienced appeared to arise in conjunction with an increased awareness of impermanence. In particular, participants attributed their participation in MAT to a greater appreciation of the uncertainty of life (subordinate theme $4 \mathrm{a}$ ) and the fact that the present moment never stands still. As demonstrated by the following extracts, participants appeared to regard their growing awareness of impermanence as a positive experience:

Things are always shifting. Nothing stays still, not even for a moment. Yes, I see that now. It's true. It's definitely true. There's no knowing what tomorrow will hold (participant 3)

Impermanence is the way things are ...I am going to try to be more in the here and now. Who knows what the future holds? I mean, I've still got to plan, you know, because you've got to. But there's actually no point really. I don't want to wish my life away (participant 7)

In addition to a greater understanding of the uncertainty of life, part of the participants' growing appreciation of impermanence appeared to manifest as an increased awareness of death (subordinate theme 4b). Again, participants appeared to relate to this as a positive experience, and all participants appeared to derive motivation and a greater sense of life perspective from understanding that death is a matter of when, rather than if:

When you know, I mean really know, that death is something that you are definitely going to have to face, it puts everything in perspective (participant 1)

Death is a matter of when, and not if. It's strange but I find this really uplifting (participant 4) 
There is no time to fool about really. You know, death can happen [at] any time. I've been given quite a wakeup call (participant 6)

When I forget [to be mindful] and get [absorbed] back in myself, I stop and think about death. It helps me to see the big picture (participant 8)

\section{Increased Sense of Citizenship}

Coupled with an increased awareness of impermanence, the sense of being on a spiritual journey appeared to instill in participants a greater sense of citizenship. More specifically, all participants reported a greater motivation to contribute towards the well-being of society (subordinate theme 5a). As demonstrated by the following excerpts, this motivation appeared to stem from an understanding by participants that they have a role in society, and that through their actions, they can influence the people and situations around them:

A lot of the things people get involved with aren't all that important. Me and my pals have a tendency to get caught up in our own world and not see the [big] picture. I want to change that now. I want to reach out and help others. It's hard to explain. Everybody has got their fair share of problems. It's important that I remember this (participant 1)

I've got something to give. I've got a role to play in helping [other people] (participant 3)

If I think positively, I can make things better. I don't just mean for me but for everybody. I can change things around here (participant 10)

Consistent with this greater motivation to contribute towards the well-being of society, participants 4 and 5 had made the decision to undertake paid work. Participants 4 and 5 appeared to be uplifted and derive a great deal of satisfaction from this decision, but they also appeared to be concerned as to whether it was a sensible long-term choice:

I've recently taken a job at [employers name redacted]. It's been three years since I've worked but I'm getting back into it. I'm really enjoying it ... I take lots of breaks. I pace myself ... [but] I'm worried I've made the right choice, and I'm worried about what will happen when this [MAT] program finishes. I hope I haven't jumped in too soon...But I'm just going with the flow. It's such a relief to be off the benefits. I mean, I'm still getting my disability money, but that's all I'm getting now (participant 4)

I've gone back to my old job. I'm taking it easy, just three afternoons [each week] at the moment. It's good. It's nice to see them all again. It feels good to give something. And it's good to get paid too. I hope I don't go back to how I was. I can't go back there. This meditation is keeping me afloat (participant 5)

As intimated by the content of some of the excerpts included under subordinate theme 5a, participants reported that MAT helped them to develop a greater sense of compassion (subordinate theme 5b). Examples of some of the phrases utilised by participants in this respect were 'help others' (participants 1, 4, 6, 9 and 10), 'reach out' (participants 1, 2, 8 and 10), 'duty to help' (participants 5, 6 and 10), 'feel others' pain' (participants 2 and 8 ) and 'feel empathy' (participants 3 and 9). Participant 9 described this greater sense of compassion as follows:

It's strange but when I think more about others, I feel better about myself. It's a struggle at first but then it gets easier. It becomes more natural. I see people and I want to help [them]...[Compassion] makes me much more forgiving (participant 9)

\section{Discussion}

In the present study, IPA was used to analyse the experiences of ten individuals with FMS that participated in an 8-week MAT programme. Participants were randomly selected from the intervention arm of an RCT evaluating the effectiveness of MAT as a treatment for FMS. All ten participants provided rich and detailed accounts of their experiences, and the following five super-ordinate themes (each comprising two subordinate themes) emerged from the dataset: (i) reservations about participating, (ii) improvements in psychosomatic well-being, (iii) spiritual growth, (iv) awareness of impermanence and (v) increased sense of citizenship.

In respect of the first super-ordinate theme of reservations about participating, other studies have likewise reported that specific population groups harbour reservations about receiving an MBI. For example, a qualitative study exploring how individuals with severe health anxiety (i.e. hypochondriasis) experience MBCT found that some participants were sceptical and uncertain about mindfulness, believing it was unscientific and might involve chanting with bells (Williams et al. 2011). Although understanding and awareness of mindfulness is likely to improve as it becomes more readily utilised in applied psychological settings, the fact that the migration of mindfulness from Eastern contemplative traditions has only occurred in earnest within the last two decades, means that it is understandable that some individuals in the West have reservations and/or inaccurate views about the nature of the practice. Notwithstanding this, to the authors' knowledge, the association made by almost all participants in the present study between mindfulness and the supernatural has not been reported in any previous qualitative or quantitative studies of mindfulness. 
A likely explanation for the prevalence of this view amongst the current group of participants is that a number of individuals attended the same FMS self-help groups, and knowing that the research project was scheduled to take place, it is likely that participants discussed and shared their (erroneous) views about mindfulness in advance of volunteering for the study. However, irrespective of how these views originated, this finding suggests that there is clearly a need to raise awareness about mindfulness in specific clinical and socio-demographic groups, and in the wider population more generally.

As part of the reservations that participants had towards mindfulness, half of the participants expressed a fear of MAT actually causing them to lose their diagnosis of FMS (subordinate theme $1 \mathrm{~b}$ ). Previous research has demonstrated that individuals with FMS often experience difficulty in (i) understanding their symptoms, (ii) receiving a diagnosis of FMS and (iii) having their needs and symptoms understood by both medical professionals and family members (Dennis et al. 2013; Hickie et al. 2004; Peterson 2007). Consequently, it is unsurprising that individuals with FMS place importance on the diagnostic label and that they derive some degree of relief from being informed that their symptoms correspond to a 'valid' medical condition (Hughes et al. 2005; White et al. 2002).

Under such circumstances, the fear of some participants that MAT might be effective in removing their symptoms (and FMS diagnosis) does not, by default, imply that the current population group (and FMS sufferers more generally) prefer to avoid paid work and/or specific societal responsibilities. However, given the association between FMS and usage of state benefits (in particular disability benefits) (SicrasMainar et al. 2009; Wolfe et al. 1997b), a slightly more sceptical perspective might deem that this specific study outcome adds credence to the view that a small proportion of individuals with FMS 'hide' behind their diagnosis and use it as a means of avoiding social and civic responsibility.

The second super-ordinate theme identified in the current study was that participants experienced improvements in psychosomatic well-being. Although a small number of participants specifically reported reductions in pain intensity and/or frequency, most participants experienced that MAT improved their ability to cope with pain (i.e. rather than decrease the intensity of pain per se). Consistent with the findings of other qualitative studies of MBIs involving individuals with pain disorders (e.g. Morone et al. 2008), participants attributed their improved pain-coping skills to the process of mindfully observing uncomfortable somatic sensations. Mindfulness is understood to increase perceptual distance from painful and/or distressing sensory and psychological stimuli, and this perceptual gap is believed to help objectify pain and thus ameliorate its impact on psychosocial functioning (Singh et al. 2008; Van Gordon et al. 2015). Unsurprisingly and consistent with a number of recent quantitative studies of MBIs involving individuals with FMS (Davis and Zautra 2013; Henke and Chur-
Hansen 2014; Lauche et al. 2013), participants reported that this greater ability to cope with pain lead to improvements in quality of life including increased levels of (i) self-efficacy, (ii) happiness, (iii) energy and motivation and (iv) sleep quality.

In terms of seeking to connect and understand their various experiences of MAT, participants made it clear that the aforementioned improvements in quality of life did not originate in isolation from the spiritual growth that was identified and reported as part of the third super-ordinate theme. Spiritual growth has occasionally been identified as an outcome of studies of first-generation MBIs (e.g. Roth and Stanley 2002; Mackenzie et al. 2007). However, consistent with the findings of the present study, the more open and explicit focus in MAT on spiritual development appeared to foster a greater degree of spiritual curiosity (subordinate theme $3 \mathrm{a}$ ), including the sense of being on a spiritual journey (subordinate theme $3 b$ ). Outcomes of spiritual growth have been reported in previous qualitative studies of MAT involving (i) individuals with issues of depression, anxiety and stress (Shonin et al. 2014a) and (ii) middle-hierarchy office managers (Shonin and Van Gordon 2015). These earlier MAT studies reported that increased spirituality helped to improve life perspective and provide a buffer against loneliness, negative affect and low sense of purpose. The collective findings from qualitative investigations into MAT (including findings from the current study) are consistent with outcomes from cross-sectional studies involving individuals with fibromyalgia in which a positive association between spirituality and positive affect, and a negative association between spirituality and depressionanxiety symptoms, has been identified (see review by Moreira-Almeida and Koenig 2008).

In addition to mindfulness, a central focus of MAT is teaching the principles of, and providing guidance for meditating upon, impermanence. As implied by the extracts of participants that were included as part of super-ordinate theme 4 (see 'Results' section), the Buddhist notion of impermanence refers to the fact that (i) phenomena are in a constant state of flux, (ii) life is (therefore) highly uncertain, (iii) all phenomena and living beings must eventually die and/or dissolve and (iv) since phenomena (including sentient beings) are in a constant state of change, they lack a permanently existing 'self' (i.e. they are of the nature of 'non-self') (Shonin et al. 2014b).

According to a Buddhist model of mental illness, an experiential understanding of impermanence and non-self are prerequisites for cultivating psycho-spiritual well-being (Shonin et al. 2014b). In the opinion of the present authors, empirical investigation into the applications and health benefits of impermanence and non-self remains under-developed. Nevertheless, the few studies that have been conducted in this area indicate that the 'practices' of impermanence and non-self may have therapeutic utility. For example, non-attachment to self and experience is correlated with higher levels of subjective well-being, pro-social behaviour and eudemonic well- 
being, and with lower levels of fatalistic outlook, intimacy avoidance, dissociation and alexithymia (Sahdra et al. 2010; Sahdra et al. 2015). Similarly, in previous qualitative studies of MAT, participants have assigned importance and meaning to their meditation-related experiences of impermanence and non-self and attributed these experiences to gains in subjective well-being (Shonin and Van Gordon 2015; Shonin et al. 2014a). According to Shonin and Van Gordon (2015), understanding that the notions of permanence and a self that exists independently (i.e. of all other phenomena) are logically implausible helps people to (i) change their perspective on life and appreciate that it is a time-limited occurrence, (ii) avoid becoming self-absorbed and/or self-obsessed, (iii) engage in meaningful activities and interpersonal interactions, and (iv) become more 'other-centred'.

The fifth and final master theme to emerge from the dataset was an increased sense of citizenship. Here, participants reported that MAT helped them to (i) feel and understand that they have a role in society, (ii) have confidence that they can influence their immediate and wider social environment, (iii) be more willing to make meaningful contributions towards the welfare of society (including opting to take-up paid work in the case of two participants), and (iv) feel motivated to support others. These findings are consistent with the significant emphasis placed in MAT on compassion and on helping participants understand the benefits to be derived from engaging with, and contributing to, community and societal welfare. The inclusion in MAT of dedicated teachings and meditations on compassion follows the traditional Buddhist model of teaching and practising spiritual development, wherein compassion assumes a central role (Shonin et al. 2014b).

Based on a recent systematic review of Buddhist-derived compassion (and loving-kindness) meditation intervention studies, compassion meditation has been shown to foster improvements in (but not limited to) (i) positive and negative affect, (ii) psychological distress, (iii) positive thinking, (iv) interpersonal relations and (v) empathic accuracy (see Shonin et al. 2015). By becoming increasingly aware of the needs and suffering of others, it is understood that individuals are better able to add perspective to their own problems and suffering, which helps to dismantle self-obsessed maladaptive cognitive structures and self-disparaging schemas (Gilbert 2009). Compassion meditation has also been shown to foster greater affection towards others that, in turn, helps to augment social-connectedness and prosocial behaviour (Hutcherson et al. 2008; Leiberg et al. 2011).

The rationale behind including techniques designed to foster compassion and citizenship in the MAT teaching syllabus is solely based on the fact that such aptitudes are associated with improved levels of subjective well-being and psychosocial functioning (Shonin et al. 2015). Indeed, participants are left to evaluate how to apply such teachings and practices in their own life situation, and they are not provided with guidance in terms of which activities and/or societal responsibilities would be suitable for their particular circumstances. Furthermore, participants are informed that premature and/or over-engagement in physical, social and compassionate activities could be counter-indicative to their overall levels of psychological well-being. Thus, given the fact that MAT does not guide or explicitly encourage participants to assume specific roles or duties (including voluntary or unpaid work), it is promising that some participants in the present study felt able and equipped to return to paid work and that others had the inspiration and/or intention to find ways of being more actively involved in their local and wider community.

FMS is a complex and poorly understood psychosomatic pain condition. As noted earlier, the illness has been the subject of controversy, both in terms of the alleged lack of interest or capability of the medical community to understand and support patients with FMS, and the burden that such individuals place upon economic and healthcare resources. Given the lack of convincing data for the effectiveness of extant pharmacological and non-pharmacological FMS treatments, there is a need to formulate and empirically evaluate novel interventional approaches. The modified version of MAT employed in the present study was experienced as an acceptable and accessible intervention by individuals with FMS, and participants likewise reported experiencing improvements in psychosomatic and psycho-spiritual well-being.

Nevertheless, as with all qualitative studies, the findings do not provide robust evidence as to the efficacy of the intervention for all individuals with FMS, and irrespective of efforts to 'bracket off' the epistemological and ontological stance of the research team, the nature of IPA means that there can never be complete certainty that any disconnect between participants' experiences and their subsequent interpretation has been removed (Shonin and Van Gordon 2015). Further empirical (qualitative and quantitative) investigations are warranted in order to further evaluate the potential utility of MAT (and other purpose-designed MBIs) for treating FMS and for changing the attitudes of some individuals with FMS towards societal participation and community engagement.

\section{Compliance with Ethical Standards}

Conflict of Interest The authors declare that they have no competing interests.

\section{References}

American Psychiatric Association. (2010). American Psychiatric Association practice guideline for the treatment of patients with major depressive disorder (3rd ed.). Arlington: American Psychiatric Publishing. 
Branco, J. C., Bannwarth, B., Failde, I., Abello Carbonell, J., Blotman, F., Spaeth, M., ... Matucci-Cerinic, M. (2010). Prevalence of fibromyalgia: a survey in five European countries. Seminars in Arthritis and Rheumatism, 39, 448-55.

Britton, W. B., Haynes, P. L., Fridel, K. W., \& Bootzin, R. R. (2012). Mindfulness-based cognitive therapy improves polysomnographic and subjective sleep profiles in antidepressant users with sleep complaints. Psychotherapy and Psychosomatics, 81, 296-304.

Canzonieri, A. M., Pollak, D. F., Oliveira, P. J., Costa, M. E., \& Natour, J. (2013). Evaluation of socio-demographic variables, psychiatric comorbidity, and pain in fibromyalgia patients. Annals of the Rheumatic Diseases, 71, 756.

Chiesa, A., \& Serretti, A. (2011). Mindfulness-based interventions for chronic pain: a systematic review of the evidence. Journal of Alternative and Complementary Medicine, 17, 83-93.

Cramer, H., Haller, H., Lauche, R., \& Dobos, G. (2012). Mindfulnessbased stress reduction for low back pain. A systematic review. BMC Complementary and Alternative Medicine, 12, 162.

Creswell, J. W. (2007). Qualitative inquiry and research design: choosing among five approaches (2nd ed.). London: Sage.

Davis, M. C., \& Zautra, A. J. (2013). An online mindfulness intervention targeting socioemotional regulation in fibromyalgia: results of a randomized controlled trial. Annals of Behavioral Medicine, 46, 273284.

Dennis, N. L., Larkin, M., \& Derbyshire, S. W. G. (2013). 'A giant mess' - making sense of complexity in the accounts of people with fibromyalgia. British Journal of Health Psychology, 18, 763-781.

Gilbert, P. (2009). Introducing compassion-focused therapy. Advances in Psychiatric Treatment, 15, 199-208.

Hamill, R., Carson, S., \& Dorahy, M. (2010). Experiences of psychosocial adjustment within 18 months of amputation: an interpretative phenomenological analysis. Disability and Rehabilitation, 32, 729 740 .

Häuser, W., Wolfe, F., Tölle, T., Üçeyler, N., \& Sommer, C. (2012). The role of antidepressants in the management of fibromyalgia syndrome: a systematic review and meta-analysis. CNS Drugs, 26, 297-307.

Henke, M., \& Chur-Hansen, A. (2014). The effectiveness of mindfulnessbased programs on physical symptoms and psychological distress in patients with fibromyalgia: a systematic review. International Journal of Wellbeing, 4, 28-45.

Hickie, I., Pols, R. G., Koschera, A., \& Davenport, T. (2004). Why are somatoform disorders so poorly recognized and treated? In G. Andrews \& S. Henderson (Eds.), Unmet need in psychiatry: problems, resources, responses (pp. 309-323). Cambridge: Cambridge University Press.

Hughes, G., Martinez, C., Myon, E., Taïeb, C., \& Wessely, S. (2005). The impact of a diagnosis of fibromyalgia on health care resource use by primary care patients in the UK: an observational study based on clinical practice. Arthritis and Rheumatism, 54, 177-183.

Hutcherson, C. A., Seppala, E. M., \& Gross, J. J. (2008). Lovingkindness meditation increases social connectedness. Emotion, 8, $720-724$.

Jones, K. D., Sherman, C. A., Mist, S. D., Carson, J. W., Bennett, R. M., \& Li, F. (2012). A randomized controlled trial of 8-form Tai chi improves symptoms and functional mobility in fibromyalgia patients. Clinical Rheumatology, 31, 1205-1214.

Langhorst, J., Klose, P., Dobos, G. J., Bernardy, K., \& Häuser, W. (2013). Efficacy and safety of meditative movement therapies in fibromyalgia syndrome: a systematic review and meta-analysis of randomized controlled trials. Rheumatology International, 33, 193-207.

Lauche, R., Cramer, H., Dobos, G., Langhorst, J., \& Schmidt, S. (2013). A systematic review and meta-analysis of mindfulness-based stress reduction for the fibromyalgia syndrome. Journal of Psychosomatic Research, 75, 500-510.
Leiberg, S., Klimecki, O., \& Singer, T. (2011). Short-term compassion training increases prosocial behavior in a newly developed prosocial game. PLoS ONE, 6(3), e17798.

Mackenzie, M. J., Carlson, L. E., Munoz, M., \& Speca, M. (2007). A qualitative study of self-perceived effects of mindfulness-based stress reduction (MBSR) in a psychosocial oncology setting. Stress and Health, 23, 59-69.

Moreira-Almeida, A., \& Koenig, H. G. (2008). Religiousness and spirituality in fibromyalgia and chronic pain patients. Current Pain and Headache Reports, 12, 327-332.

Morone, N. E., Lynch, C. S., Greco, C. M., Tindle, H. A., \& Weiner, D. K. (2008). "I felt like a new person." the effects of mindfulness meditation on older adults with chronic pain: qualitative narrative analysis of diary entries. The Journal of Pain, 9, 841-848.

National Institute for Health and Clinical Excellence (NICE). (2009). Depression: management of depression in primary and secondary care. London: Author.

Nüesch, E., Häuser, W., Bernardy, K., Barth, J., \& Jüni, P. (2013). Comparative efficacy of pharmacological and nonpharmacological interventions in fibromyalgia syndrome: network meta-analysis. Annals of the Rheumatic Diseases, 72, 955-962.

Peterson, E. L. (2007). Fibromyalgia - management of a misunderstood disorder. Journal of the American Academy of Nurse Practitioners, 19, 341-348.

Rimes, K. A., \& Wingrove, J. (2013). Mindfulness-based cognitive therapy for people with chronic fatigue syndrome still experiencing excessive fatigue after cognitive behaviour therapy: a pilot randomized study. Clinical Psychology \& Psychotherapy, 20, 107-117.

Roth, B., \& Stanley, T. W. (2002). Mindfulness-based stress reduction and healthcare utilization in the inner city: preliminary findings. Alternative Therapies in Health and Medicine, 8, 60-66.

Sahdra, B. K., Shaver, P. R., \& Brown, K. W. (2010). A scale to measure non-attachment: a Buddhist complement to western research on attachment and adaptive functioning. Journal of Personality Assessment, 92, 116-127.

Sahdra, B. K., Ciarrochi, J., Parker, P. D., Marshall, S., \& Heaven, P. (2015). Empathy and nonattachment independently predict peer nominations of prosocial behavior of adolescents. Frontiers in Psychology, 6, 263.

Sandelowski, M., \& Barroso, J. (2002). Reading qualitative studies. International Journal of Qualitative Methods, 1, 74-108.

Schaefer, C., Chandran, A., Hufstader, M., Baik, R., McNett, M., Goldenberg, D., ... Zlateva, G. (2011). The comparative burden of mild, moderate and severe fibromyalgia: results from a crosssectional survey in the United States. Health and Quality of Life Outcomes, 9, 71. DOI: 10.1186/1477-7525-9-71.

Scott, M., \& Jones, K. (2014). Mindfulness in a fibromyalgia population. Journal of Alternative and Complementary Medicine, 20, A94 A95.

Shonin, E., \& Van Gordon, W. (2015). Managers' experiences of Meditation Awareness Training. Mindfulness, 4, 899-909.

Shonin, E., Van Gordon, W., \& Griffiths, M. D. (2014a). Meditation Awareness Training (MAT) for improved psychological wellbeing: a qualitative examination of participant experiences. Journal of Religion and Health, 53, 849-863.

Shonin, E., Van Gordon, W., \& Griffiths, M. D. (2014b). The emerging role of Buddhism in clinical psychology: toward effective integration. Psychology of Religion and Spirituality, 6, 123-137.

Shonin, E., Van Gordon, W., Compare, A., Zangeneh, M., \& Griffiths, M. D. (2015). Buddhist-derived loving-kindness and compassion meditation for the treatment of psychopathology: a systematic review. Mindfulness, 6, 1161-1180.

Sicras-Mainar, A., Rejas, J., Navarro, R., Blanca, M., Morcillo, A., Larios, R., ... Villarroya, C. (2009). Treating patients with fibromyalgia in primary care settings under routine medical practice: a claim 
database cost and burden of illness study. Arthritis Research and Therapy, 11, R54. DOI:10.1186/ar2673.

Sim, J., \& Madden, S. (2008). Illness experience in fibromyalgia syndrome: a metasynthesis of qualitative studies. Social Science \& Medicine, 67, 57-67.

Singh, N. N., Lancioni, G. E., Wahler, R. G., Winton, A. S., \& Singh, J. (2008). Mindfulness approaches in cognitive behavior therapy. Behavioural and Cognitive Psychotherapy, 36, 659-666.

Singh, N. N., Lancioni, G. E., Winton, A. S. W., Karazsia, B. T., \& Singh, J. (2014). Mindfulness-Based Positive Behavior Support (MBPBS) for mothers of adolescents with autism spectrum disorders: effects on adolescents' behavior and parental stress. Mindfulness, 5, 646657.

Smith, J. A. (1995). Semi-structured interviewing and qualitative analysis. In J. A. Smith, R. Harre, \& L. Van Langenhove (Eds.), Rethinking methods in psychology (pp. 9-26). London: Sage.

Smith, J. A. (1996). Beyond the divide between cognition and discourse: using interpretative phenomenological analysis in health psychology. Psychology and Health, 11, 261-271.

Smith, J. A. (2004). Reflecting on the development of interpretative phenomenological analysis and its contribution to qualitative research in psychology. Qualitative Research in Psychology, 1, 39-54.

Smith, J. A., Flowers, P., \& Larkin, M. (2009). Interpretative phenomenological analysis. Theory, method and research. London: Sage Publications Ltd.

Stange, J. P., Eisner, L. R., Hölzel, B. K., Peckham, A. D., Dougherty, D. D., Rauch, S. ... Deckersbach, T. (2011). Mindfulness-based cognitive therapy for bipolar disorder: effects on cognitive functioning. Journal of Psychiatric Practice, 17, 410-419.

Van Gordon, W., Shonin, E., Sumich, A., Sundin, E., \& Griffiths, M. D. (2014). Meditation Awareness Training (MAT) for psychological wellbeing in a sub-clinical sample of university students: a controlled pilot study. Mindfulness, 5, 381-391.
Van Gordon, W., Shonin, E., \& Griffiths, M. (2015). Towards a secondgeneration of mindfulness-based interventions. Australian and New Zealand Journal of Psychiatry, 49, 591-591.

Vøllestad, J. (2015). Mindfulness- and acceptance-based interventions in the treatment of anxiety disorders. In E. Shonin, W. Van Gordon, \& M. D. Griffiths (Eds.), Mindfulness and Buddhist-derived approaches in mental health and addiction. Gewerbestrasse: Springer. doi:10.1007/978-3-319-22255-4_1.

White, K. P., Nielson, W. R., Harth, M., Ostbye, T., \& Speechley, M. (2002). Does the label "fibromyalgia" alter health status, function, and health service utilization? A prospective, within-group comparison in a community cohort of adults with chronic widespread pain. Arthritis Care and Research, 47, 260-265.

Williams, M. J., McManus, F., Muse, K., \& Williams, J. M. (2011). Mindfulness-based cognitive therapy for severe health anxiety (hypochondriasis): an interpretative phenomenological analysis of patients' experiences. British Journal of Clinical Psychology, 50, 379397.

Wolfe, F. (2009). Fibromyalgia wars. Journal of Rheumatology, 36, 671678.

Wolfe, F., Anderson, J., Harkness, D., Bennett, R. M., Caro, X. J., Goldenberg, D. L., ... Yunus, M. B. (1997). A prospective, longitudinal, multicenter study of service utilization and costs in fibromyalgia. Arthritis and Rheumatism, 40, 1560-1570.

Wolfe, F., Anderson, J., Harkness, D., Bennett, R. M., Caro, X. J., Goldenberg, D. L., ... Yunus, M. B. (1997). Work and disability status of persons with fibromyalgia. The Journal of Rheumatology, 24, 1171-1178.

Wolfe, F., Brähler, E., Hinz, A., \& Häuser, W. (2013). Fibromyalgia prevalence, somatic symptom reporting, and the dimensionality of polysymptomatic distress: results from a survey of the general population. Arthritis Care and Research, 65, 777-785.

Yardley, L. (2000). Dilemmas in qualitative health research. Psychology and Health, 15, 215-228. 